\title{
The Relationship of Coalition on Employee Spiritual Engagement: Interplay of Organisational Politics
}

Isaac Onyeyirichukwu Chukwuma ${ }^{1}$, Emmanuel Kalu Agbaeze ${ }^{*}, 1$, Nkiru Peace Nwakoby², Gertrude Chinelo Ugwuja ${ }^{1}$, Fidelis Odinakachukwu Alaefule ${ }^{1}$, Ifeanyi Leo Madu ${ }^{3}$

${ }^{1}$ University of Nigeria, Department of Management, Nigeria

${ }^{2}$ Nnamdi Azikiwe University, Department of Entrepreneurship Studies, Nigeria

${ }^{3}$ Gregory University, Department of Business Administration, Nigeria

\section{A R T I C L E IN F O}

Article history:

Received: 28 August, 2019

Accepted: 04 October, 2019

Online: 22 November, 2019

Keywords:

Coalition

Employee spiritual engagement

Organizational politics

\begin{abstract}
A B S T R A C T
The objective of the study was to establish the relationship between coalition and employee spiritual engagement. The research was quantitative, and data was administered and retrieved from employees at the selected private radio firms. Content validity was utilised to ascertain the validity of the instrument, and the reliability of the instrument was established using Cronbach's alpha coefficient. Kendall's tau_b correlation was used to shows the result of the bivariate relationship between coalition and employee spiritual engagement ( $p>0.05)$; hence, we accepted the null hypothesis. To know how much variance in employee spiritual engagement can be clarified by coalition, a simple linear regression was performed; with a result of 0.1 (percent), it was evidenced that coalition had no effect on employee spiritual engagement. The finding of the study showed that there is no statistical relationship between coalition and employee spiritual engagement. The result of this study also bears practical implications; executives should understand that organisations cannot achieve a zero-level coalition activity. Although this behaviour via the results does not possess a statistical relationship, executives should articulate its optimized use within acceptable terms.
\end{abstract}

\section{Introduction}

Politics has existed for centuries; however, the logical investigation of politics in organisation merely started taking shape about thirty years ago [1]. [2] posits that the purpose behind the paucity of study on organisational politics is likened to the focused study of politics in the regions of sociology, social psychology, and political science. During the late 1970s and mid1980s, milestone works emerged that made way for the contemporary investigation of organisational politics [1, 3-5]; though the presence of politics inside organizations is known, the quest for a superior comprehension of how it affects employee engagement is developing as a significant challenge for executives in the 21 st century.

Organisational politics from a global perspective create irresolute reactions since employees take a juxtapose stand on the

\footnotetext{
* Corresponding Author: Emmanuel Kalu Agbaeze, University of Nigeria, emmanuel.agbaeze@unn.edu.ng
}

concept; contingent upon the specific point of view they have, and it is critical to state that the level of organisational politics varies amongst organizations. The fact remains that organisations have elements of micro and macro political activities that influence their activities $[6,7]$.

Organisational politics is perceived as either a symptom of social influence processes intentionally executed to achieve shortterm or long-term advantages for the organisation or a self-serving activity that conflicts with the organisational objectives [8, 9]. Organisational politics is also seen as the management of influence to achieve goals not authorised by the organisation or to achieve authorised goals though non-authorised influence; via controlling information channels, managing impression, and forming a coalition [1, 10, 9]. [11] observes that organisational politics are significant since it gives a comprehension of the informal procedures of conflicts and co-operation in organisations, and their impact on the employees' engagement. 
In Nigeria, the presence of organisational politics highlights that employees are exceptionally sensitive to behaviours in their workpalce, and their perspectives and discernments are influenced by the prevailing culture in the organisation. Organisational politics is overwhelming in Nigeria because the macro environment thrives with political interests; hence, organisational politics rule, characterize and restructure the state of organisational choices and activities in Nigeria [12].

Lately, there is a developing focus on the complexities of organisational politics. Extant literature has examined organisational politics behaviour (i.e., controlling information, creating obligation) primarily on the premise that such behaviour hinders optimal organisational goals and work-place related variables $[13,14]$, while this may be validated with their findings, other scholars; $[15,16]$ found contrary and positive results. While these studies have evaluated organisational politics behaviour at individual levels (i.e., impression management, creating obligation) in the organisation, which have produced equivocalness, the current study questions and examines the interplay of organisational politics at the group level (i.e., coalition) and its relationship on employee spiritual engagement. More so, extant studies have generally been focused with the results of employee performance [17-20], as opposed to the conditions or the unique situation (i.e., employee spiritual engagement) that propels performance, this study addresses that. Finally, the relationship between creating coalition and employee spiritual engagement has not been extensively examined in empirical studies, and the Nigerian context, hence the need for this study.

Coalition in this study context consists of persons within an organisation that influence goals via informal structure [21]. The forming of coalitions in organisations is mostly activated via conflicting goals. At the group level (i.e., coalition), the expressed objectives of the organisation are not the absolute organisational objective [22, 23]; denoting that implicit objective of the employees who sustain informal authority structure in the organisation via forming a coalition, compliment or undermine stated goals. Hence, the complimenting or undermining of stated goals is contingent on the level of dominance possessed by the coalition, which may influence employee spiritual engagement via perceived goal complexity.

The necessity for a spiritual connection has become significant to employees, mainly because of recurrent changes in organisational structure (i.e., political activities; coalition), which may result in feelings of insecurity for one's place in the organisation [24]. Employee spirituality engagement has gained a global corporate focus. It features a global development in which the focus has moved to the perspective that work ought to be significant and meaningful. This focus is presently on a spiritual paradigm; as a recent developing paradigm in which much advancement with regard to the understanding of the employee spiritual engagement are evolving [25]. Studies reveal that employees find it hard to disconnect their spiritual lives from their workplace environment [26]. They acknowledge that blending spirituality in the work environment will provide them significant and purposeful life. This also possesses a ripple effect in that the organization experiences improved profits, increased morale and performance, and reduced absenteeism [27].

To remain relevant in this contemporary dynamic business environment, organisations are constantly seeking for engaged employees. In this context, engagement denotes employees' holistic commitment to their work via the application of discretionary effort [28]. This emerging concept has birthed terms, such as Faith at Work, Workplace Spirituality, Employee Spiritual Engagement [29]. The factor of employee spirituality encapsulates the notion that all employees have their internal inspirations, facts, and desires to be explored in professional activities that provide significant meaning to life. Hence, when employees are spiritually engaged, "work" connotes an important experience and encounter; when it is acknowledged as a calling, a consecrated obligation, a service opportunity or a higher purpose $[30,31]$.

As private radio broadcasting firms contribute significantly towards the economic, socio-cultural, and political development and sustenance, continued studies within this industry are critical. It is also significant that employees realise that the pressure to remain useful and relevant in a capitalist economy (i.e., Nigeria) that is highly dynamic has majorly influenced organisational political activities (i.e., coalition). In making sense of this dynamics and continuing to maintain productively, employees develop a mindset of wholeness, values, and discovering purpose and significance at work; which are the parameters of spiritual engagement [32]. Hence, when coalitions create or fail to create an atmosphere that value perspectives such as significant and fulfilling work, a consciousness of life, connectedness, and compassion, what effect or nature of relation exist?

There is presently paucity of information and studies on the relationship between coalition and employee spiritual engagement. The present research is an empirical attempt to explore the relationship of coalition on employee spiritual engagement within the context of private radio broadcasting firms in Southeast Nigeria. The research hypothesis for this study is:

Ho: there is no relationship between coalition and employee spiritual engagement.

$\mathbf{H}_{1}$ : there is a relationship between coalition and employee spiritual engagement.

The underlying hypothesis of this research is that the axiomatic conclusion that coalition affects employee spiritual engagement may not be true. The research is an empirical study of employees experience in private radio broadcasting firms in Southeast Nigeria.

This research is significant in several ways: First, it highlights the statistical relationship between coalition and employee spiritual employee within their work context. Secondly, it examines the construct with the potency of the social exchange theory. Thirdly, the study states the practical implication of the result which will help firms in achieving sustainable advantage. The study is expected to influence policy restructuring in handling coalition activities. 
The remaining section of this study will be under these major sections; literature review, methodology, results, discussion, conclusion, recommendation, limitations and directions for further research, references, and appendices.

\section{Literature Review}

\subsection{Coalition}

Over time, the concept of coalition has remained ambiguous with respect to relevance and meaning within organisation theory. From the work of [33] who acknowledged coalition between but not within organisations, to the work of [34] who coined the term "dominant coalition" and "inner circle," to the phase of the adoption of political science and social psychology method to organisational behaviour [35,36]. And most recently its relevance to the political arena, where coalition influences all sectors of a nations' sustenance. Notwithstanding the extant literature on coalition, it has still not produced a new perspective to understanding organisational behaviour [37].

Organisational power originates from numerous sources; a significant source is who you know and how accessible are information within your organisation; hence, forming a coalition are blueprints of relationships between employees [38].

Coalition has over time become one of the most widely recognized and famous element of every organisation's workforce, which fulfill the following psychological functions of; character and confidence, defense mechanism, risk elimination, affiliation needs, social reality, information need, political maneuvering [39, 40]. It is thus viewed as a principal device and instrument utilized by employees in organisations to understand as well as to influence management decisions that are misaligned to their goals.

Coalition formation though evidently present is not always officially recognized by organisation, such coalition are sometimes the unofficial determinants of the activities of such organisations as they represent, serve, and affect organisational activities; playing different roles such as been the initiators (those who request that certain things be done, users (they utilize the things obtained), influencers (they influence decision making), approvers (they approve things to be done in organisations), deciders (they select those that will carry out the desired task), and gatekeepers (they control the inflow of information) [41].

Much of the work that gets done in organisations is influenced through the activities of the coalition. Forming coalition serves three significant roles. First, they convey privileged information. Also, they enable employees to access assorted skill sets. Finally, they can create, control, or influence authority [38]. Forming coalition amongst other things ensures employee gain greater bargaining power, minimize discrimination, heighten sense of security, disseminate information, and safeguards members ambition; hence motivating employee to discharge their responsible with an assurance of comrades, oneness and unity, which ultimately advance organisational sustainability, nonetheless, the same assurance gives them a platform to resist employers activities that are unfavourable to their interest [38, 42].
Notwithstanding the ambiguity to the definition of coalition, recurrent terms in diverse definition have acknowledged that coalitions are clusters of persons who temporarily collaborate to achieve a target aim via informal structure [43, 44, 45]. Coalitions are valuable for achieving a wide scope of objectives that span past the limit of any individual member in the organisation. These objectives range from knowledge sharing to facilitation of services, from sensitization and training to advocacy for policy (regulatory) changes [46]. Whatever definition of coalitions is utilised, understanding coalitions give understanding to employees' behaviour in organisational structures.

Coalitions play an integral role in organisations operations; a dominant coalition can influence the goals of an organisation [47]; this is mostly achieved via informal, rather than formal channels. By forming a coalition, employees have the opportunity to affect organisational policies, decisions, and compensation structures. Coalition seeks relatively broad and strategic support of their objectives. It occurs more frequently in organisations with routine and standardized task and resource interdependencies.

Effective coalition building addresses an unpredictable cluster of challenges, which includes optimising the communication measures; strategically, communication is a major trigger for diverse levels of employee engagement. Optimal communication activities range from coordinating networks among like-minded employees; encouraging dialogue and building support among diverse interest [48]. Convincing employees to join a coalition requires subtlety, and strategically creating messages that aligns with the mission (shared purpose and anticipated rewards) of the prospective employee [49]. While coalitions seek to increase the scope and influence of their activities, the building of trust and members access to relevant resources and policy network is of paramount. Arguably, coalition members are more likely to access resources denied to nonmembers, as the formation of coalition mostly alters the distribution of resources, and modus-operandi of the organisation, which may influence employee's spiritual engagement. Although studies have been executed with respect to the activities of coalition in organisations setting $[41,23]$, there is paucity or no studies on the relationship of coalition on employee spiritual engagement.

\subsection{Employee spiritual engagement}

Scholarly endeavours to incorporate spirituality into an organisational setting with the contention that spirituality not only impacts employees but also significantly influences organisational and managerial fields, prompted the development of the new field of inquiry called workplace spirituality [50]. However, it is important to stress that employee spiritual engagement is not restricted to religious tradition, employee spiritual engagement is not about getting employees into a particular arrangement of religious convictions [51], rather it focuses on individual and organisational values and practices; it is about helping employees explore their core values and work towards objectives that are personally meaningful, it denotes empowering employees to connect their inner lives and individual interests with their everyday work [52]. 
Numerous researchers contend that the major reasons for increased focus on employee spiritual engagement are the changing work and lifestyle, the rise of self-exploration, and a developing pattern to examine life importance and values by organisation scholars [50]. [53] asserts that life's demand stretches out beyond the materialistic aspects, and it is necessary to address the spiritual dimension of employees to accomplish better outcomes in an organisational setting.

In [54], the asserts that employee spiritual engagement possesses the following four dimensions; (a) Compassion (denotes empathy or care for the travail of others, often including a craving to help. [54] defines this dimension of employee spiritual engagement as a profound awareness of and compassion towards others and a craving to relieve their travailing; that leads to responsibility for others who are less fortunate or travailing). (b) Mindfulness (this dimension of employee spiritual engagement is characterised as a condition of inward awareness in which one is conscious of one's thoughts and actions. It is about an employee's mind being present, not meandering with past, future thoughts or distractions [54]. (c) Meaningful work, [54] characterises meaningful work as one's experience in which work is a significant and meaningful part to his/her life, this meaning is beyond the tangible rewards and creates a sense of energy and joy at work). (d) Transcendence (A significant component of employee spiritual engagement connotes whether employees can translate their work practices and their organisations' tasks in sacred terms [55].

In [56], the authors posits that employees have adapted and possess the required cognitive mechanisms for observing, evaluating, and regulating the suitable pattern of response to coalitions. These adaptations allow an employee to recalibrate their level of spiritual engagement as coalitions grow, function, and influence organisations goals and activities.

In today's world, an increasing number of employees are seeking more than just a monetary reward. Reward in the form of purposeful, motivational, impactful, and meaningful work is the optimal goal [57]. [58,59] posit that employee spirituality is not about theoretical and religious construct. Rather, it is focused on employees who find strength, purpose, meaning, and completeness in their work [60,61]. It also encircles employees sharing and encountering connection, attraction, and comradeness with persons within their work environment.

Notwithstanding the acknowledged equivocalness in the definition of employee spirituality [62] a recurrent theme has consistently occurred in the attempted definition, namely the meaningfulness and purpose in the workplace and employees' life, a feeling of interconnectedness and of belonging to the workforce, and personal joy and fulfilment $[60,61,59]$.

Studies reveal that a work environment that encourages employees spiritual engagement can provide advantages in the areas of process improvement, creativity, customer service, satisfaction, team performance, honesty and trust, personal fulfillment, and commitment, which may result in optimised organisational performance $[63,27]$. [64] posits that employee spirituality is focused on recognizing that employees attend to their task at work with more than their bodies and minds; they possess individual talents and uniqueness, which ensures optimal performance when properly engaged.

\subsection{Coalition and employee spiritual engagement}

Notwithstanding the ambiguity to the definition of a coalition, recurrent terms in the diverse description have acknowledged that coalitions are clusters of persons who temporarily collaborate to achieve a target aim via informal structure [44, 45]. Coalition formation though evidently present is not always officially recognized by an organisation; such coalition is sometimes the unofficial determinants of the activities of such organizations as they represent, serve, and affect organizational activities and may influence employee spiritual engagement.

Employees have over time, evolved in developing an effective cognitive mechanism for identifying, examining, evaluating, and regulating the appropriate level of spiritual engagement to coalition activities [56]. This adaptability helps employees to regularly recalibrate their spiritual engagement level as coalitions grow, function, and influence organizations objectives and activities. Having acknowledged employee spiritual engagement as a topical construct, there is an increasing focus amongst researchers to empirically explore the relationship between employee spiritual engagement and different organizational actions (i.e., coalition) [65-69, 52, 70, 71]. Nonetheless, there is paucity in the literature concerning the relationship between coalition and employee spiritual engagement.

Employees are continually seeking a work environment whose objectives align with their values in other to fully encounter significance, and meaning in their task. While this is possible, the relationship in social interactions process and the interplay of organizational politics (i.e., coalition) in the work environment requires empirical credence to ascertain its influence on employee spiritual engagement.

\subsection{A social exchange theory perspective of coalition and employee spiritual engagement}

Social exchange theory (SET) is a crucial conceptual model for articulating workplace behaviour, SET views social activities (e.g., coalition) as a series of exchange which are interdependent; the behavior (e.g., level spiritual engagement) of one party (e.g., employee) is contingent on the actions (e.g., coalition activity) of another $[72,14]$. Hence, a perceived alignment in values via actions executed generates an obligation (e.g., target level spiritual engagement) to reciprocate in kind; this also denotes a high level of unpredictability in employee spiritual engagement as the perception and interpretation of an aligned values or meaningfulness varies amongst employees in an organisations [73, 74]. Hence, the operationalised and covet structure of coalition activities and its ambiguous value to employees makes it difficult to predict employees level of spiritual engagement in a coalition work context $[75,76]$.

Employee spiritual engagement and social exchange perspectives share similar logic; specifically, both perspectives 
acknowledge that perception to activities of workplace coalition is connected with employee subjectivity [14]. We propose that coalition have a direct effect on employee spiritual engagement. Nonetheless, the employee spiritual engagement level is intentionally exercised via the prerogative of employees' discretionary effort.

\section{Methodology}

The population of this study was employees of private radio broadcasting firms in Southeast (i.e., Abia, Anambra, Enugu, and Imo state) Nigeria. Twelve (12) private radio broadcasting firms in Southeast were selected for this study based on their popularity within their locality. By focusing on the private radio broadcasting sector, we avoided the possibility for unobserved differences that mark the government broadcasting industry. The population of the full-time staff in the selected private radio firms was 383 ; hence a census technique was applied, with questionnaires distributed to a population of 383 employees, and 359 complete responses were retrieved, denoting a response rate of 94\% (approximate). Inferential statistical analysis was conducted using Kendall's tau b correlation, and linear regression analysis was used to establish the relationship, and the degree to which the variance in employee spiritual engagement can be attributed to coalition, using SPSS. The participants were assured of complete confidentiality. These steps reduced the possibility of their responses been subjected to social desirability or acquiescence biases [77].

\section{Results}

\subsection{Validity and reliability of the questionnaire}

The validity of the instrument was established using content validity. The reliability of the instrument was assessed using Cronbach's alpha coefficient. The reliability results are indicated in Table 1. Coalition was measured with five items adopted from previous research viz [78]; the Cronbach's alpha coefficient for coalition is regarded as good (0.728). Employee spiritual engagement was measured with five items adopted from previous research viz $[79,28]$; the Cronbach's alpha coefficient for employee spiritual engagement is also good (0.792); this implies that the instruments are reliable and valid for this study.

\begin{tabular}{lc}
\multicolumn{2}{c}{ Table 1: Reliability assessment. } \\
\cline { 2 - 2 } Variable & Cronbach's Alpha \\
\hline Coalition & 0.728 \\
Employee spiritual & 0.792 \\
engagement & \\
\hline
\end{tabular}

\subsection{Correlation between coalition and employee spiritual engagement}

Table 2 reflects Kendall's tau_b correlation between coalition and employee spiritual engagement. Table 2 shows the result of the bivariate relationship between coalition and employee spiritual engagement via Kendall's tau_b correlation. Table 2 shows that there is no significant relationship $(\mathrm{p}>0.05)$ between coalition and employee spiritual engagement, and the strength of the association between forming coalition and employee spiritual engagement is very weak $(r=.046)$. Since, $\mathrm{p}$ $(0.238)>0.05$, we accept the null hypothesis and conclude that there is no relationship between coalition, and employee spiritual engagement.

Table 2: Kendalls' tau_b correlation results for coalition, and employee spiritual engagement $(n=359)$.

\begin{tabular}{llll}
\hline Construct & Category & Coalition & $\begin{array}{l}\text { Employee } \\
\text { spiritual } \\
\text { engagement }\end{array}$ \\
\hline Coalition & $\begin{array}{l}\text { Kendalls' } \\
\text { tau_b }\end{array}$ & 1 & 0.046 \\
& Sig. (2 tailed) & - & 0.238 \\
& $N$ & 359 & 359 \\
Employee & Kendalls' & 0.046 & 1 \\
spiritual & tau_b & & \\
engagement & Sig. (2 tailed) & 0.238 & - \\
& $N$ & 359 & 359 \\
\hline
\end{tabular}

\subsection{Linear regression analysis}

A simple linear regression analysis was conducted to predict the influence of coalition on employee spiritual engagement (see Table 3). To know how much variance in employee spiritual engagement can be clarified by coalition, a simple linear regression was performed. As can be seen from Table 3, coalition contributes 0.1 (percent) to the variance in employee spiritual engagement, also the $\mathrm{p}(0.503)>0.05$. Hence, coalition has no relationship with employee spiritual engagement.

Table 3: Linear regression analysis results, where coalition is the independent variable, and employee spiritual engagement is the dependent variable.

\begin{tabular}{lllllll}
\hline Variable & & & & \multicolumn{3}{r}{ Coalition } \\
\hline $\begin{array}{l}\text { Employee } \\
\text { spiritual } \\
\text { engagement }\end{array}$ & 0.035 & 0.001 & 0.449 & 0.037 & 0.670 & 0.503 \\
\hline
\end{tabular}

$R$, R-value; $\mathrm{R}^{2}, \mathrm{R}$-squared value; $\mathrm{F}, \mathrm{F}$-value; $\beta$, beta-value; $P$, significance.

\section{Discussion}

Significant emphasis has been placed on the need to understand the dimensions of organisational political activities (i.e., coalition) $[19,20]$. The research objective was to determine the relationship between coalition and employee spiritual engagement. This study reveals interesting findings; first, our finding linked coalition with employee spiritual engagement, and found no relationship, indicating that coalition has no statistical relationship with employee spiritual engagement. This finding also contradicts the axiom that coalition inhibits employee spiritual engagement, and should be avoided at all cost. In general, employees' spiritual engagement may be filtered through discretionary effort in responding to coalition activities. Nonetheless, employees been human coupled with the dynamic nature of the work environment might, in rare occasion exercise or fail to exercise discretionary effort in response to coalition behaviour and still create a neutral or zero relationships. 
Beyond the fundamental bivariate relationship, our finding also contradicts the core of the social exchange theory [64, 63] connoting that employees spiritual engagement level is mostly influenced by their interpretation and perception of the benefits offered in a coalition activity; while this may be factual to an extent, employees ability to exercise discretionary effort may not be influenced by such interpretation and perception.

The result of this study also bears practical implications; executives should understand that organisations cannot achieve a zero-level coalition activity and that this behaviour via the results does not possess a statistical relationship. Hence executives should articulate its optimized use within acceptable ethical terms.

\section{Conclusion}

The research contributes to the paucity of empirical knowledge on the relationship between coalition and employee spiritual engagement. Specifically, the study found no relationship between coalition and employee spiritual engagement. From a practical viewpoint, the result of the study holds implication for private radio firms, which should be considered.

\section{Recommendation}

The researchers recommend that private radio broadcasting firms should adopt a culture of transparency and predictability in the process of resource allocation, in addition to a peer review authorization process. This will aid in down-playing the emergence of a dominant coalition that may deter optimal achievement of the organizational goals.

\section{Limitation and Direction for Future Research}

The study has acknowledged the following limitations; firstly, the scope of the study with respect to the geographic area and industry may compromise the external validity and applicability of its result; therefore, there is need to be careful in generalizing the findings to other geography and industry. Also, a commonmethod variance may influence the results, due to the census technique utilized and the self-administration of the questionnaire. Despite the acknowledged limitations, the study holds significant implications for radio firms that desire sustainable posterity. Also, there is a need to explore this relationship in other countries and industry, which will aid in an extensive comparative study, as well as meta-analysis; this will further the theoretical and practical relevance of the construct under study.

\section{Conflict of Interest}

The authors declare no conflict of interest.

\section{References}

[1] T. Mayes, W. Allen, "Toward a definition of organizational politics" Academy of Management Review, 2(4), 672-678, 1977.

[2] P. Block, "The empowered manager: positive political skills at work" San Francisco: Jossey-Bass, 1988.

[3] B. Bacharach, J. Lawler, "Power and politics in organizations" San Francisco: Jossey-Bass, 1980.

[4] H. Mintzberg, "The organization as political arena" Journal of Management Studies, 22(2), 133-154, 1985.
[5] J. Pfeffer, "Managing with Power" Boston: Harvard Business School Press, 1992.

[6] O. Bernard, N. Augustina, "The influence of power and politics in organizations" International Journal of Academic Research in Business and Social Sciences, 4(7), 164-183, 2014.

[7] E. Mutambara, C. Botha, C. Bisshoff, "Perception of organizational politics at a national electricity provider in Southern African Development Community (SADC)" Journal of Economics, 6(3), 291-301, 2015.

[8] P. Block, "The empowered manager: positive political skills at work" San Francisco: Jossey-Bass, 1988.

[9] G. Gotsis, Z. Kortezi, "Ethical considerations in organizational politics: expanding the perspective" Journal of Business Ethics, 93, 497-517, 2010.

[10] Drory, E. Vigoda-Gadot, "Organizational politics and human resource management: A typology and the Israeli experience" Human Resource Management Review, 20, 194-202, 2010.

[11] E. Vigoda-Gadot, A. Drory, "Handbook of organizational politics" Cheltenham: Edward Elgar, 2006.

[12] E. Ben, M. Ik, "The scope and patterns of organisational politics in Nigeria" International Journal of Business Administration, 3(3), 41-49, 2012.

[13] E. Vigoda-Godat, I. Talmund, "Organizational politics and job outcomes: the moderating effect of trust and social support" Journal Applied and Social Psychology, 40(11), 2829-2861, 2010.

[14] Ying-Ni, Y. Chih-Long, L. Hung, "Transformational leadership and job involvement: The moderation of emotional contagion" Military Psychology, 24(4), 382-396, 2012.

[15] C. Treadway, A. Hochwarter, R. Ferris, J. Kacmar, C. Douglas, P. Ammeter, R. Buckley, "Leader political skill and employee reactions" Leadership Quarterly, 15, 493-513, 2004.

[16] D. Fedor, J. Maslyn, S. Farmer, K. Bettenhausen, "Perceptions of positive organizational politics and their impact on organizational outcomes" Journal of Applied Social Psychology, 38, 76-96, 2008.

[17] R. Cropanzano, C. Howes, A. Grandey, P. Toth, "The relationship of organizational politics and support to work behaviors, attitudes, and stress" Journal of Organizational Behavior, 18, 159-180, 1997.

[18] A. Witt, "Enhancing organizational goal congruence: a solution to organizational politics" Journal of Applied Psychology, 83, 666-674, 1998.

[19] Witt, C. Andrews, M. Kacmar, "The role of participation in decision-making in the organizational politics-job satisfaction relationship" Human Relations, 53, 341-358, 2000.

[20] E. Vigoda-Gadot, "Internal politics in public administration systems: An empirical examination of its relationship with job congruence, organizational citizenship behavior, and in-role performance" Public Personnel Management, 29, 185-210, 2000.

[21] P. Timothy, K. James, L. Robyn, C. Darren, "The implications of coalition forms for work role innovation, resource reallocation, and performance" In: Research in Personnel and Human Resources Management. Emerald Group Publishing Limited, pp. 65-97, 2014.

[22] C. Perrow, "Complex organizations: A critical essay" $3^{\text {rd }}$ ed. New York: McGraw Hill, pp. 1-307, 1993.

[23] M. Bowler, "Organizational Goals versus the dominant coalition: a critical view of the value of organizational citizenship behavior" Institute of Behavioral and Applied Management, 258-273, 2006.

[24] P. Heaton, J. Schmidt-Wilk, F. Travis, "Constructs, methods, and measures for researching spirituality in organizations" Journal of Organizational Change Management, 17(1), 62-82, 2004.

[25] M. Fourie, "Spirituality in the workplace: an introductory overview" In die Skriflig, 48(1), 1-8, 2014.

[26] E. Zimmerman, "The many delicate issues of spirituality in the office" New York times, 2004. Available at: https://www.nytimes.com/2004/08/15/jobs/the-many-delicate-issues-ofspirituality-in-the-office.html [Accessed 23 May 2019].

[27] C. Litzsey, "Spirituality in the workplace and the implications for employees and organizations" M.Sc. Dissertation, Graduate School: Southern Illinois University, 2006.

[28] H. Macey, B. Schneider, "The meaning of employee engagement" Industrial and Organizational Psychology, 1(1), 3-30, 2008.

[29] D. Miller, "God at work: the history and promise of the faith at work movement" Oxford University Press, pp. 1-232, 2006.

[30] F. Paloutzian, A. Emmons, G. Keortge, "Spiritual well-being, spiritual intelligence, and healthy workplace policy. In: Giacolone, R., Jurkiewicz, C. (Eds.), Handbook of workplace spirituality and organizational performance. M.E. Sharpe: New York, 2003.

[31] L. Reave, "Spiritual values and practices related to leadership effectiveness. The Leadership Quarterly, 16(5), 655-687, 2005. 
[32] J. Weinberg, B. Locander, “Advancing workplace spiritual development: a dyadic mentoring approach" The Leadership Quarterly, 25(2), 391-408, 2014.

[33] G. March, A. Simon, "Organizations" New York: Wiley, 1958.

[34] D. Thompson, "Organizations in action: social science bases of administrative theory" New York: McGraw-Hill, 1967.

[35] J. Pfeffer, "New directions for organization theory: problems and prospects" New York: Oxford University Press, pp. 1-276, 1997.

[36] M. Roberts, "Alliances, coalitions and partnerships: building collaborative organizations" St. Paul, MN: New Society Publishers, pp. 1-176, 2004.

[37] S. William, P. Jone, P. Lyman, "The concept of coalition in organization theory and research. Academy of Management Review, 256-268, 1985.

[38] B. Talya, E. Berrin, "Organizational behavior" Irvington, NY: Flat World Knowledge, 2010.

[39] K. Baker, "Tapping into the power of informal groups" Supervisory Management, 26(2), 18-25, 1981.

[40] E. Han, "The informal organization you've got to live ith" Supervisory Management, 28(10), 25-28, 1983.

[41] O. Michael, "Industrial marketing management, principles, perspectives and practices" First Fountain Printing and Publishers Co. Awka- Nigeria, p. 62, 2010.

[42] S. Bishal, "The effect of trade unionism on workers; a case study on PAM" A Project Report at University of Applied Sciences, 2012.

[43] L. Hemphill, S. McGreal, J. Berry, S. Watson, "Leadership, power and multisector urban regeneration partnerships" Urban Studies, 43(1), 59-80, 2006.

[44] M. Le-Ber, O. Branzei, "Towards a critical theory of value creation in crosssector partnerships" Organization, 17(5), 599-629, 2010.

[45] M. Shumate, A. O'Connor, The symbiotic sustainability model: conceptualizing ngo-corporate alliance communication" Journal of Communication, 60(3), 577-609, 2010.

[46] L. Cohen, N. Baer, P. Satterwhite, "Developing effective coalitions: an eight step guide" In: Wurzbach, M. (Eds.), Community health education and promotion: A Guide to Program Design and Evaluation. Gaithersburg, Md: Aspen Publishers Inc., pp. 144-161, 2002.

[47] M. Cyert, G. March, "A behavioral theory of the firm" Englewood Cliffs, NJ: Prentice-Hall, 1963.

[48] J. Rosner, "Communicating difficult reforms: eight lessons from Slovakia" In: Odugbemi, S., Jacobson, T. (Eds.): Governance reform under real-world conditions: citizens, stakeholder, and voice. Washington, D.C.: The International Bank for Reconstruction and Development / The World Bank, pp. 395-396, 2008.

[49] K. Bert, "Collective political action" In: Sears, D., Huddy, L., \& Jervis, R. (Eds.), Oxford Handbook of political psychology, pp. 670-709, 2003.

[50] C. Sheng, M. Chen, "Workplace spirituality scale design: the view of oriental culture" Business and Management Research, 1(4), 46-62, 2012.

[51] N. Fagley, M. Adler, "Appreciation: a spiritual path to finding value and meaning in the workplace" Journal of Management, Spirituality and Religion, 9(2), 167-186, 2012.

[52] S. Lee, K. Lovelace, C. Manz, "Serving with spirit: an integrative model of workplace spirituality within service organizations" Journal of Management, Spirituality and Religion, 11(1), 45-64, 2014.

[53] B. Thaker, "Approaches to implement spirituality in business" Journal of Human Values, 15(2), 185-198, 2009

[54] P. Petchsawang, D. Duchon, "Measuring workplace spirituality in an Asian context" Human Resource Development International, 12(4), 459-468, 2009.

[55] D. Grant, K. O'Neil, L. Stephens, "Spirituality in the workplace: new empirical directions in the study of the sacred" Sociology of Religion, 63(5), 265-283, 2004.

[56] J. Tooby, L. Cosmides, "Evolutionary psychology and the generation of culture" Ethologv and Sociobiologv, 10, 29-49, 1989.

[57] P. Bloch, "Complexity, chaos, and nonlinear dynamics: a new perspective on career development theory" The Career Development Quarterly, 53, 194$207,2005$.

[58] J. Harrington, C. Preziosi, J. Gooden, "Perceptions of workplace spirituality among professionals and executives" Employee Responsibilities and Rights Journal, 13(30), 155-163, 2001.

[59] S. Dhiman, J. Marques, "The role and need of offering workshops and courses on workplace spirituality" Journal of Management Development, 30(9), 816-836, 2011.

[60] A. Giacalone, L. Jurkiewicz, "Toward a science of workplace spirituality" In: Gaicalone, R., Jurkiewicz, C. (Eds.), Handbook of workplace spirituality and organizational performance. M.E. Sharpe Inc.: New York, pp. 3-28, 2003.
[61] M. Kinjerski, J. Skrypnek, "Defining spirit at work: finding common ground" Journal of Organizational Change Management, 17(1), 26-42, 2004.

[62] A. Hicks, "Religion and the workplace: pluralism, spirituality, leadership" University Press: Cambridge.

[63] J. East, "A grounded study on how spirituality impacts a person's job satisfaction" Minneapolis: Capella, niversity.

[64] P. Leigh, "The new spirit at work" Training and Development, 51(3), 26-34, 1997.

[65] A. Faro, C. Campos, M. Dias, A. Brito, "Primary health care services: workplace spirituality and organizational performance" Journal of Organizational Change Management, 27(1), 59-82, 2014.

[66] S. Indartono, Z. Wulandari, "Moderation effect of gender on workplace spirituality and commitment relationship: Case of Indonesian ethics" Asian Journal of Business Ethics, 3(1), 65-81, 2014.

[67] A. Shrestha, "Workplace spirituality and employee attitudes: moderating role of organizational politics" Journal of Business and Management Research, 1(2), 33-51, 2017.

[68] L. Daniel, "Workplace spirituality and stress: Evidence from Mexico and US" Management Research Review, 38(1), 29-43, 2015.

[69] J. Byrne, M. Morton, J. Dahling, "Spirituality, religion, and emotional labor in the workplace" Journal of Management, Spirituality \& Religion, 8(4), 299-315, 2011

[70] M. Saks, "Workplace spirituality and employee engagement" Journal of Management, Spirituality \& Religion, 8(4), 317-340, 2011.

[71] J. Word, "Engaging work as a calling: Examining the link between spirituality and job involvement" Journal of Management, Spirituality \& Religion, 9(2), 147-166, 2012.

[72] R. Cropanzano, M. Mitchell, "Social exchange theory: An interdisciplinary review" Journal of Management, 31(6), 874-900, 2005.

[73] T. Hall, A. Hochwarter, R. Ferris, G. Bowen, "The dark side of politics in organizations" In: Griffin, W. O'Leary-Kelly, M. (Eds.), The dark side of organizational behavior, San Francisco: Jossey-Bass, pp. 237-261, 2004.

[74] C. Russell, S. Marie, "Social exchange theory: An interdisciplinary review" Journal of Management, 31(6), 874-900, 2005.

[75] L. Shore, L. Tetrick, P. Lynch, K. Barksdale, "Social and economic exchange: construct development and validation" Journal of Applied Social Psychology, 36(4), 837-867, 2006.

[76] E. Eyvind, A. Knut, T. Are, "Social exchange theory as an explanation of organizational citizenship behaviour among teachers" International Journal of Leadership in Education, 14(4), 405-421, 2011.

[77] P. Spector, "Method variance in organizational research: truth or urban legend?" Organizational Research Methods, 9, 221-232, 2006.

[78] L. Brown, M. Feinberg, M. Greenberg, "Measuring coalition function: refining constructs through factor analysis" Health Education and Behavior, 39(4), 486-497, 2012.

[79] J. Loehr, T. Schwartz, "The power of full engagement: managing energy, not time, is the key to high performance and personal renewal" New York: Free Press, 2003. 
Appendices

Table A: Coalition scale

Instructions: Please tick on the response that best describes your observation.

Statement

Strongly Agree Neither Disagree Strongly

Agree Agree nor Disagree

Disagree

1. Organisational leadership are influenced by informal authority

2. Informal authority determines the focus and direction of task in an organization

3. Informal authority influence interpersonal relationships in organisation

4. Coalition members are personally rewarded for the coalition involvement

5. Organisational operations are influenced by informal authority

Table B: Employee spiritual engagement scale

Instructions: Please tick on the response that best describes your observation. Statement

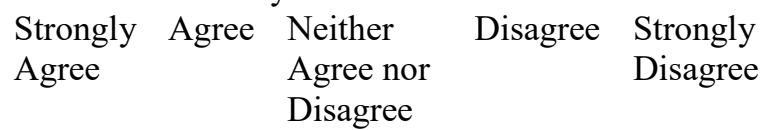

1. There is a good fit between my values and the organisation's values

2. I feel like my work is meaningful and important to this organization

3. I feel like I significantly contribute to the success of this organization

4. I understand my purpose in helping my team, and the organisation be successful

5. Overall, I get a real sense of achievement working for this organization 